\title{
Adaptive Notch Filter Bank Based Power Quality Analysis of an Ultra-High Frequency Induction Heating System
}

\author{
M. TAŞTAN
}

\begin{abstract}
Widespread use of the semiconductor switching elements of power electronics in energy systems has brought about various power quality problems. One of these significant power quality problems is the harmonics, which occur in power systems. Harmonics are generated predominantly by induction systems, arc furnaces, welding machines, static frequency converters and motor converter drivers. In this study, a power quality analysis is proposed with a Phase-Locked Loop (PLL) based Digital Adaptive Notch Filter (ANF) for the $900 \mathrm{KHz}$ Ultra-High Frequency Induction Heating System (UHFIHS), which is widely used in the industry. In this proposed method, firstly the power signal is synchronized with the fundamental frequency using PLL, and then the harmonic frequency components of the signal is obtained by the ANF. Finally, challenging factors behind the harmonic analysis, such as fundamental frequency shifting, spectral leakage and leakage effect are eliminated and thus a precise and reliable power quality analysis is conducted.
\end{abstract}

Index Terms - power quality, power system harmonics, phase locked loops, adaptive filter, electromagnetic induction.

\section{INTRODUCTION}

$\mathrm{T}$ HE RESPONSIBILITY of institutions that produce, transfer and distribute electric power, which is one of the most significant energy sources, is to ensure uninterrupted, economical, quality and highly reliable delivery of energy to the consumers. Certain devices which are connected to energy systems, and especially those with semiconductor switching elements, such as induction heating systems, arc furnaces, welding machines, static frequency converters and motor converter drivers, cause a variety of problems like shortening in the lifetime, voltage fluctuations, flickers, and more importantly, harmonics [1], [2].

Induction heating systems are normally used for fast heating applications of magnetic materials. These systems are also used for various other purposes, such as forging, melting,

M. TAȘTAN, is with Department of Electronic and Automation University of Manisa Celal Bayar, Turgutlu, Manisa, Turkey, (e-mail: mehmet.tastan@ @ cbu.edu.tr).

iD https://orcid.org/0000-0002-2306-6008

Manuscript received December 16, 2018; accepted Feb 26, 2019. DOI: $\underline{10.17694 / \text { bajece. } 498021}$ hardening, sintering and welding. Induction is one of the fastest heating systems in today's technology [3]. It has already been identified that heat treatment processes which are carried out with the UHFIHS is more cost-efficient than the other practices [4]. Moreover, the treatments carried out with the UHFIHS is faster than those performed with conventional heating systems [5]. Fast Fourier Transformation (FFT) [6], [7], [8] is widely used in harmonic analysis due to its efficiency in measurement. However, certain factors such as the incorrect selected sampling window, frequency resolution that is restricted by the windowing function and fundamental frequency deviation may result in aliasing, spectral leakage, and picket-fence effect [9], [10], [11]. All these problems cause errors in measurements of the harmonic analysis. In addition to the methods based on the Fourier Transformation, the Prony Method [12], [13], ESPRIT [14], PLL-based Methods [15], Kalman Filter [16], [17], ANN Analysis [18], Wavelet Transform Method [19], ANF [20] and similar others are also commonly used in harmonic analysis. Errors in calculation of fundamental frequency values in harmonic analyses, which are performed for non-linear loads such as induction and arc furnaces [21], result in imprecision in harmonic frequency components as well. Miscalculated fundamental frequency may cause the emergence of interharmonics, which do not exist in the signal under normal conditions. For this reason, there are a number of different methods in use to ensure proper calculation of fundamental frequency or synchronization with the fundamental frequency. PLL is among the most common methods used for this purpose. In addition, the software based PLL structure used in the proposed method is proven to be superior to the other PLL structures [22]. In this study, current and voltage data are collected for heat treatments performed with a $900 \mathrm{KHz}$ induction heating system with $2.8 \mathrm{~kW}$ power. With the PLL based digital ANF proposed for this study, the frequency and amplitude value of each harmonic component is separately calculated and the power quality analysis of the UHFIHS is performed with a high level of reliability.

The main contributions of this paper are as follows:

- The study shows that induction heating systems cause a high amount of harmonic distortion.

- The spectral leakage effect caused by the interharmonics is prevented and it makes harmonic calculation with great accuracy. 


\section{PROPOSED METHOD}

Estimation of the fundamental frequency is critical for harmonic analysis. Even a minor deviation in fundamental frequency estimation may cause significant calculation errors in results of the analysis. PLL is a closed-loop servo system, which continuously tracks the output signal in order to minimize phase errors between the input and the output signals. PLL aims to lock the frequency and phase of the feedback signal, $\mathrm{x}(\mathrm{k})$, to the phase and frequency of the input signal, $\mathrm{V}(\mathrm{t})$. The used PLL structure is identical to the PLL structure developed in [22]. The structure of the proposed software-based PLL is given in Fig. 1. This PLL structure consists of four blocks, namely, Phase Detector (PD), Frequency Divider (FD), PI and Voltage-Controlled Oscillator (VCO). The proposed PLL's superiority over the other structures widely used in the literature, such as EPLL [23] and pPLL [24], and its success against certain disturbances such as phase shifting, amplitude changing and multizero crossing, are proven as it is revealed by the real-time experiments given in [25].

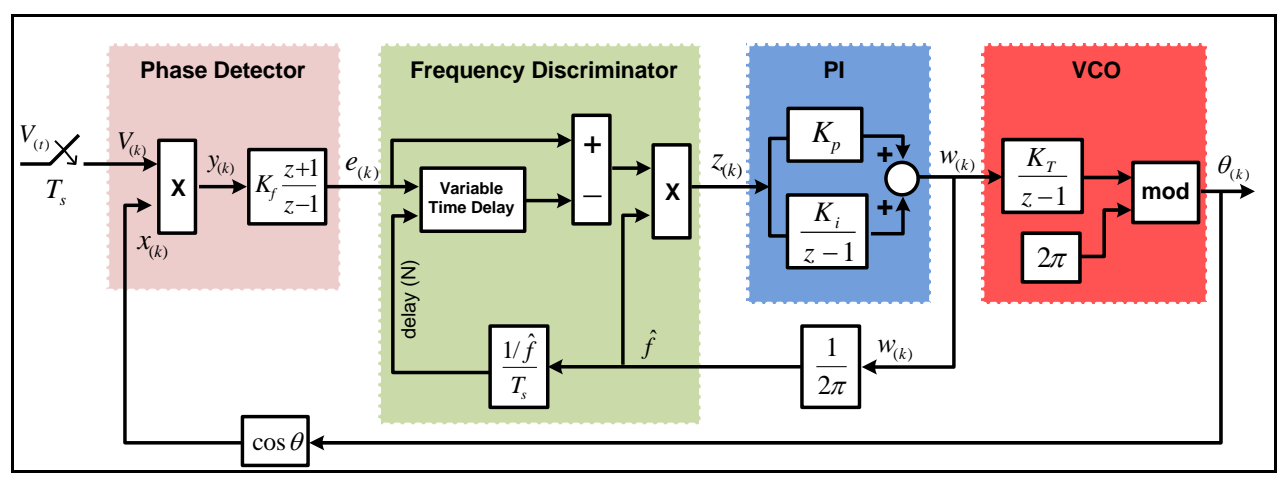

Fig.1. The Phase-Locked Loop (PLL) Block Diagram

PLL locks up the fundamental component $\left(\omega_{0}\right)$ of the power signal in input, and generates the signals specified as integer power of $\omega_{0}$, which are $\sin \omega_{0}, \sin 2 \omega_{0}, \sin 3 \omega_{0}, \ldots$, $\sin n \omega_{0}, \cos \omega_{0}, \cos 2 \omega_{0}, \cos 3 \omega_{0}, \ldots, \cos n \omega_{0}$ in output. Changes in fundamental frequency of the power sign are tracked by the PLL's digital tracker sensitively. Frequencies of sinn $\omega_{0} / \cos n \omega_{0}$ generated by the PLL can track changes in fundamental frequency even under other disturbances than the harmonics. The discrete-time transfer function for the notch filter proposed in this study and the frequency response analysis are given in [22]. In parallel with the block diagram given in Fig.2, the transfer function of the notch filter which damps the angular frequency, $\omega_{0}$, is shown in Equation 1 below:

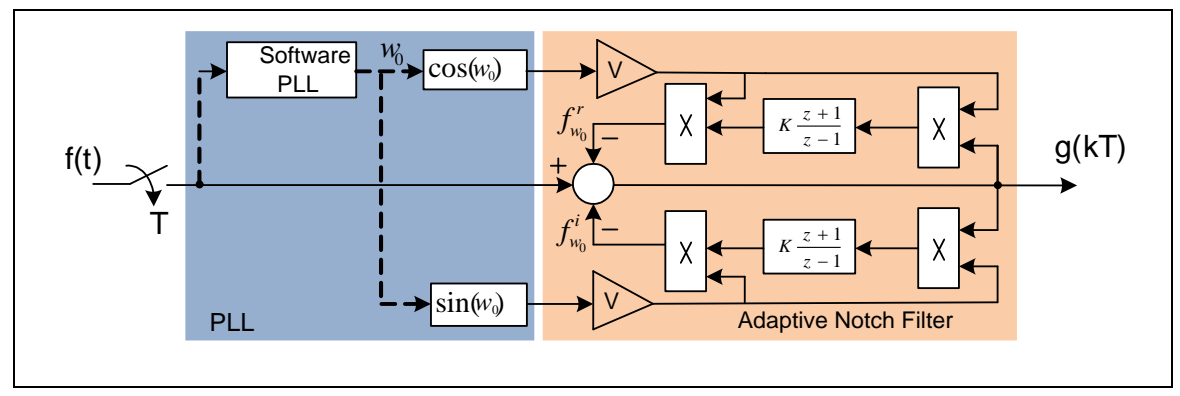

Fig.2. Digital Adaptive Notch Filter Block Diagram

$H\left(e^{j w T}\right)=\frac{\cos \omega_{\Delta} T+j \sin \omega_{\Delta} T-1}{\left\{1+2 K V^{2}\right\}\left\{\cos \omega_{\Delta} T+j \sin \omega_{\Delta} T\right\}+2 K V^{2}-1}$

where $\mathrm{T}$ is the sampling time, $\omega_{0}$ is the angular frequency of the reference signal for $\omega_{\Delta}=\omega-\omega_{0}, \omega$ is the angular frequency of the signal $\mathrm{f}(\mathrm{t}), \mathrm{V}$ is the amplitude of $\sin \omega_{0}$ and $\cos \omega_{0}$ reference signals, and $\mathrm{K}$ represents the integrator factor. According to Equation 1, $\left|\mathrm{H}\left(\mathrm{e}^{\mathrm{jwT}}\right)\right|=0$ is the equation for the angular frequency $\omega=\omega_{0}$ in $\mathrm{f}(\mathrm{t})$ input signal. This means that the $\omega_{0}$ component in $f(t)$ signal is suppressed in the output. The filter bandwidth is not affected by peripheral factors. The equation for the bandwidth is $\mathrm{BW}=\mathrm{V}^{2} \mathrm{~K}$, and the value of bandwidth can be altered by changing $\mathrm{V}$ and $\mathrm{K}$ values. Keeping the bandwidth in a short range prevents leakage of interharmonics, particularly those close to harmonic frequency components. Experimental studies for disturbances such as phase shifting, frequency deviation, multizero crossing and voltage sag, which emerge either separately or simultaneously, have proven that the proposed ANF is highly efficient in each of these situations [25]. As it is seen in Fig.3, the structure of the proposed method for power quality analysis consists of a software-based PLL and a digital 
ANF. $\mathrm{X}(\mathrm{t})$, which is applied as an input to the software-based interharmonic distortions, frequency deviation, change in amplitude values, phase shifting and multizero crossing, in addition to the harmonics. The ANF bank is composed of number "n" of adaptive notch filters with adjustable suppression frequency. In this study, 25 notch filters are used in total until the 25th harmonic. In each ANF, relevant components of the input signal, $\left(\omega_{0}, \omega_{1}, \ldots, \omega_{n}\right)$, are suppressed. The in $n \omega_{0} / \cos n \omega_{0}$ signal frequencies, which are applied to the
PLL, may include different disturbances such as notch filter, are also used as the notch filter's suppression frequency. When the fundamental frequency of the signal applied to the notch filter input changes, the suppression frequency also changes. In each filter output, the components of the input signal, An.sinn $\omega_{0} / \mathrm{Bn} \cdot \cos n \omega_{0}$ are suppressed. When the input signal of each filter output is subtracted from $x(t)$, the frequency component $\left(\omega_{n}\right)$, which is suppressed by the notch filter, is obtained.

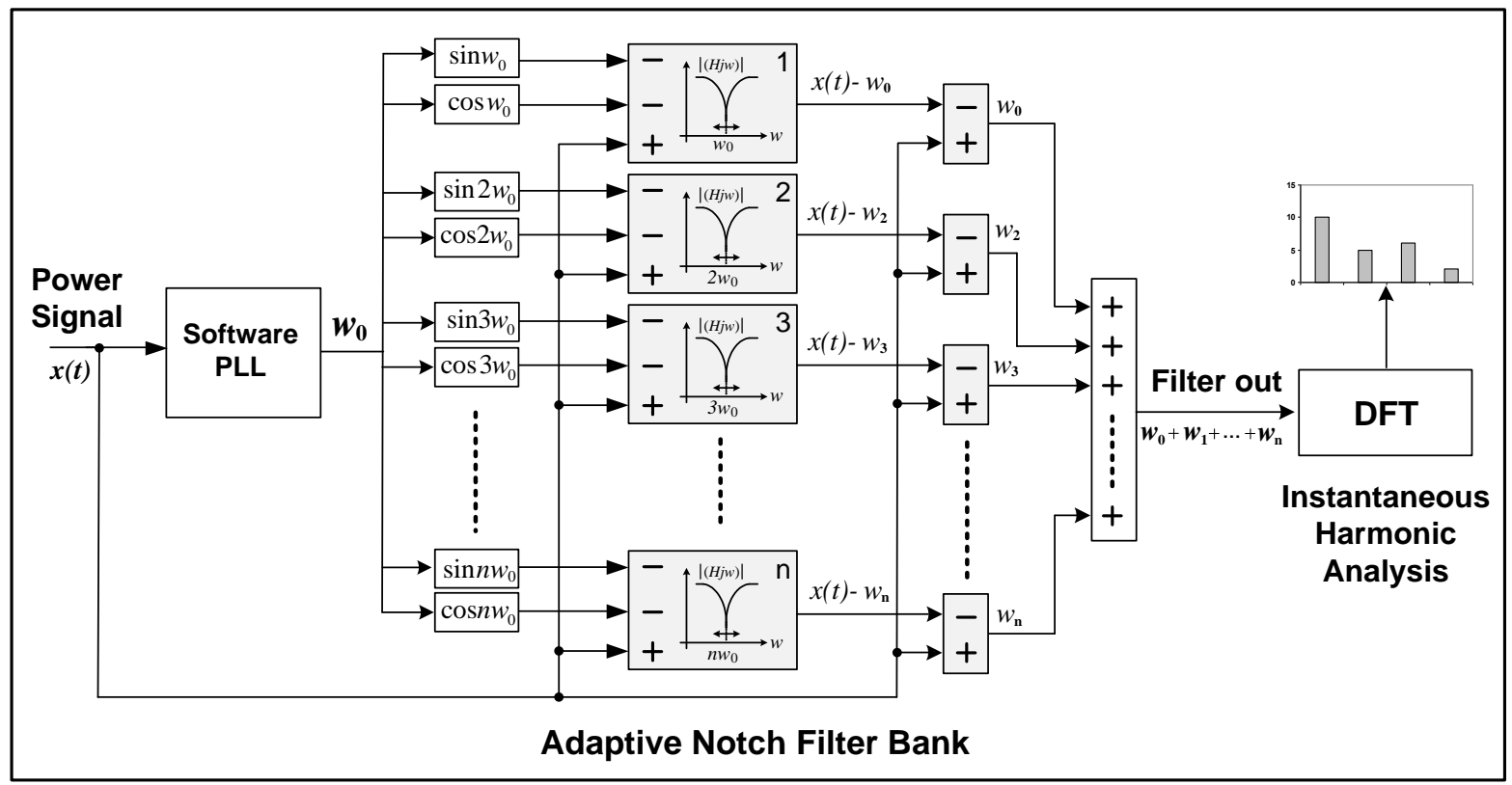

Fig.3. Structure of the PLL Based Adaptive Notch Filter Bank

In this way, each filter produces proper outputs without the impact of interharmonics or other disturbances. The sum total of all notch filter outputs gives the total value of harmonic signals that exist in the input signal. This signal, which is the sum total of the harmonics obtained in the ANF output, is subjected to a DFT calculation in accordance with the IEC standards. In this way, the amplitude values, phase angles and frequencies of the harmonics in the signal can separately be calculated in a more precise and accurate way.

\section{EXPERIMENTAL RESULTS}

The current and voltage date of the experimental studies are recorded by the LabVIEW ${ }^{\mathrm{TM}} 8.5$ graphical interface creator over the National Instruments PCI 6221 data acquisition card, with a sampling frequency equal to $f s=5000$ samples/s. The process is performed in accordance with the IEC 61000-4-30 and IEC 62053-21 standards. Fig.4 shows the visual front panel of the LabVIEW ${ }^{\mathrm{TM}}$ based measurement system.

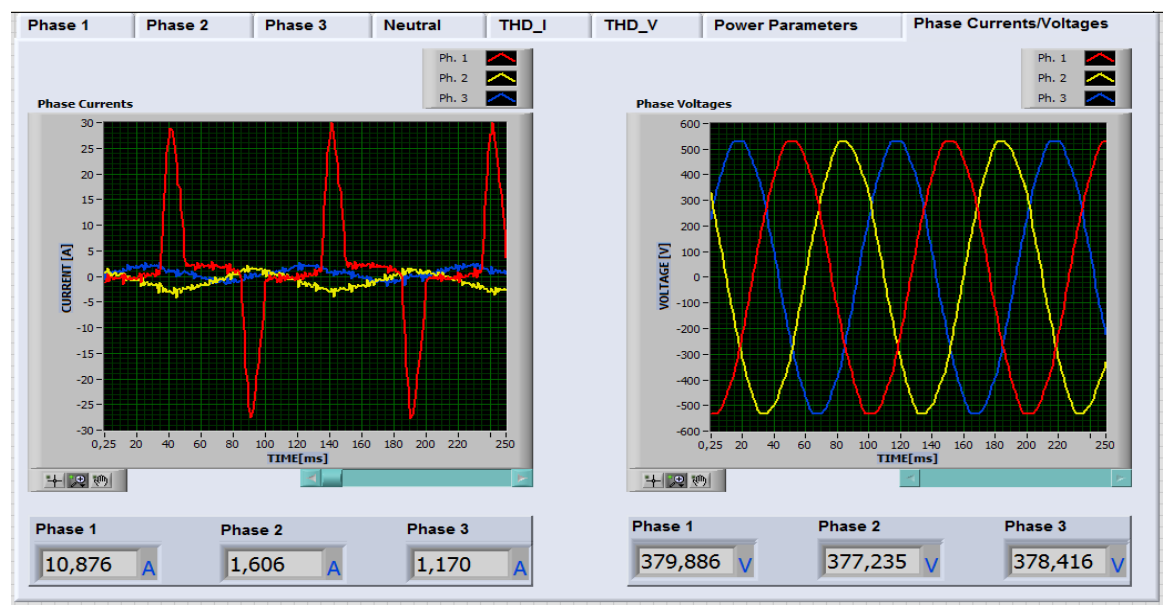

Fig.4. Front panel of the LabVIEW ${ }^{\mathrm{TM}}$ based measurement system. 
Fig.5 shows the block structure of the data acquisition system. The data obtained through this data acquisition system is filtered by passing through the PLL based ANF bank, which is prepared in MATLAB/Simulink. The fundamental frequency component, $\left(\omega_{0}\right)$, and the signal that represents the total sum of harmonics, $\left(\omega_{0}+\omega_{1}+\ldots+\omega_{n}\right)$, are subjected to the DFT analysis in accordance with the IEC 61000-4-7 standards. The amplitude values of the fundamental component and the harmonic components are obtained as a result of this analysis.

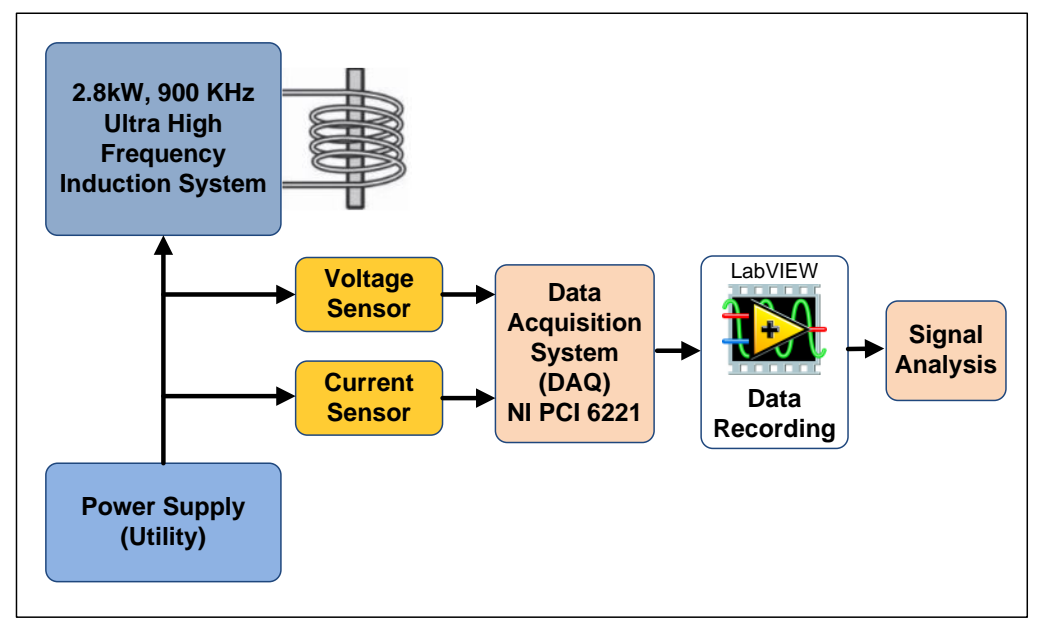

Fig.5. LabVIEW ${ }^{\mathrm{TM}}$ Based Data Acquisition System

Following the calculation of amplitude values of aforementioned components, values of other harmonic components are calculated taking the fundamental component as $1 \mathrm{Pu}$. The Total Harmonic Distortion (THD) is measured with the formula given in Equation 2. The Total Harmonic Distortion of the current is calculated with the equation below; Where;

$[\mathrm{THD}]_{\mathrm{I}}(\%)=100 x \frac{\sqrt{\sum_{h=2}^{\infty} I_{h}^{2}}}{I_{1}}$

$[\mathrm{THD}]_{\mathrm{I}}$ : Total Harmonic Distortion of the current, $I_{h}$ : Effective value of $n$. order of harmonic in the load current, $I_{1}$ : Effective value of the load current in the fundamental frequency,

h : Harmonic order.

Total harmonic distortion for the current can also be explained as the ratio of the active value of harmonic components to the active value of the fundamental component.
Coefficients of the software-based PLL and ANF used in the proposed method are given in Table 1 .

TABLE I

PLL AND ADAPTIVE NOTCH FILTER COEFFICIENTS

\begin{tabular}{|l|l|l|c|}
\hline \multicolumn{2}{|c|}{ PLL } & \multicolumn{2}{c|}{ Adaptive Filter } \\
\hline Coefficient & Value & Coefficient & Value \\
\hline $\mathrm{K}_{\mathrm{i}}$ & 1800 & $\mathrm{k}_{\mathrm{i}}$ & 0.0085 \\
\hline $\mathrm{K}_{\mathrm{p}}$ & 60 & $\mathrm{k}_{\mathrm{v}}$ & 0.125 \\
\hline $\mathrm{K}_{\mathrm{t}}$ & 1.0 & $\mathrm{~T}_{\mathrm{s}}$ & $50 \mu \mathrm{s}$ \\
\hline $\mathrm{T}_{\mathrm{s}}$ & $50 \mu \mathrm{s}$ & \multicolumn{2}{|c}{} \\
\hline
\end{tabular}

The analysis of this power signal, which involves the fundamental component and harmonic components obtained in the filter output, is conducted with the DFT method suggested by IEC. The DFT analysis took $\mathrm{N}=1000$ samples as the reference for $\mathrm{t}=0.2 \mathrm{~s}$, and used $\mathrm{T}=10 / f$ windows with $5 \mathrm{~Hz}$ resolution for $f=50 \mathrm{~Hz}$, as suggested in IEC 61000-4-7.

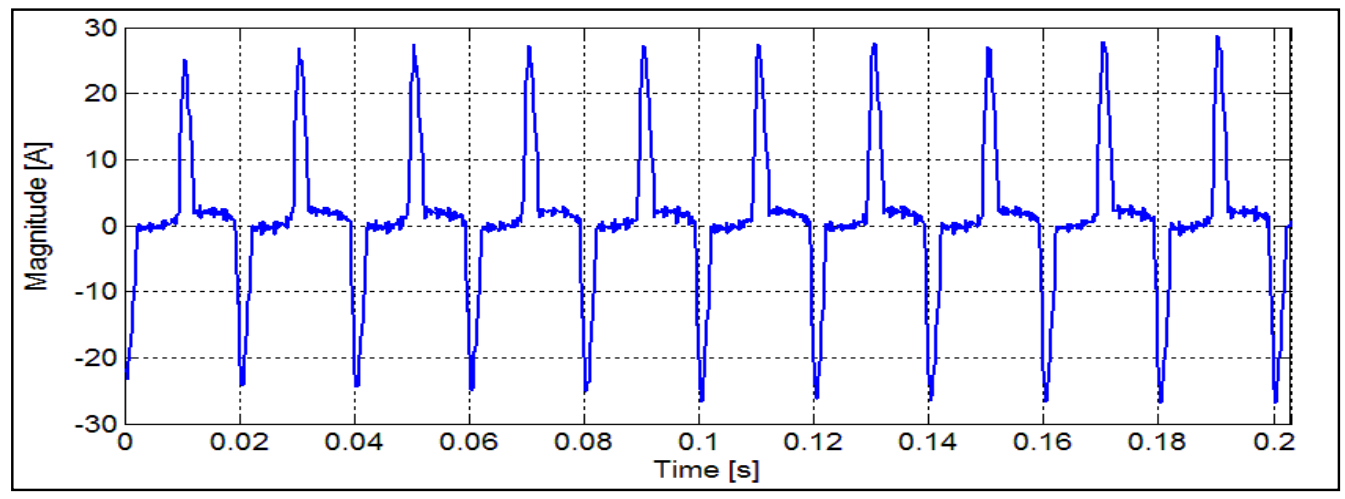

Fig.6. $\mathrm{t}=0.2 \mathrm{~s}$ Induction System Current Signal 
Fig.6 shows the sampling frequency current signal $(f s=5000)$ of a heat treatment taken from the induction system. This current signal has 10 periods and $\mathrm{T}=0.2 \mathrm{~s}$ sampling time, as required for DFT analysis. It is seen in its structure that the signal includes a large number of harmonic components in a position far from the sinusoidal structure.

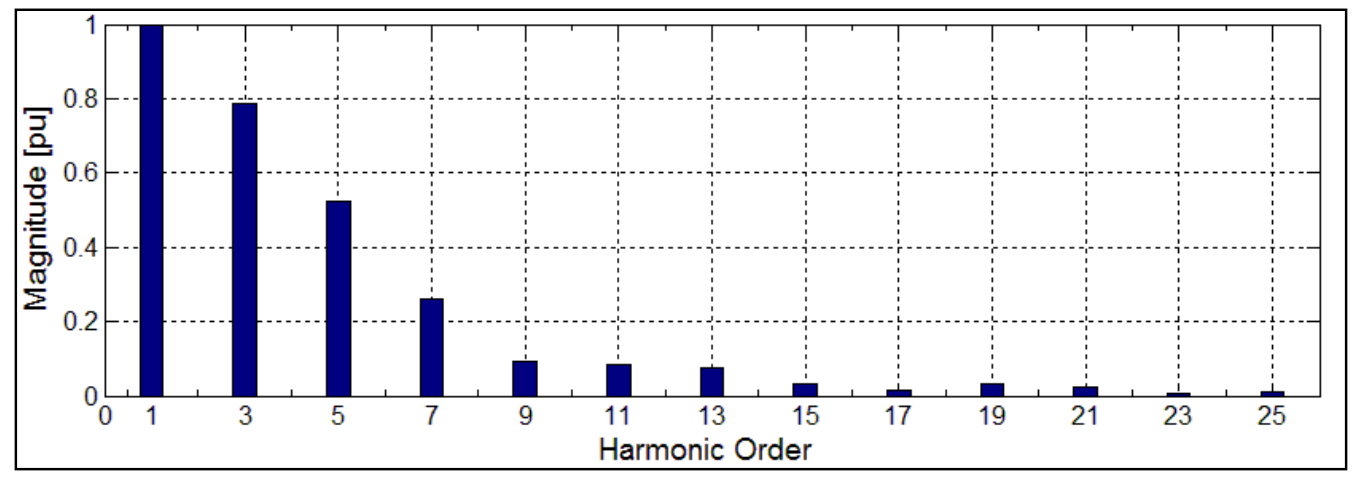

Fig.7. DFT Frequency Spectrum for Current Signal

Fig.7 shows DFT frequency spectrum of the current signal. When the DFT frequency spectrum is analyzed, it is seen that the $3 \mathrm{rd}$, 5th, and 7 th harmonic components are fairly higher than $10 \%$, while the others are below $10 \%$.

TABLE II

EFFECTIVE HARMONIC CURRENT AND HARMONIC RATIOS (\%)

\begin{tabular}{|c|c|c|c|c|c|}
\hline $\begin{array}{c}\text { Harmonic } \\
\text { Order } \\
{[\mathrm{n}]}\end{array}$ & $\begin{array}{c}\text { Harmonic } \\
\text { Current } \\
{[\mathrm{A}]}\end{array}$ & $\begin{array}{c}\text { Harmonic } \\
\text { Ratios } \\
{[\%]}\end{array}$ & $\begin{array}{c}\text { Harmonic } \\
\text { Order } \\
{[\mathrm{n}]}\end{array}$ & $\begin{array}{c}\text { Harmonic } \\
\text { Current } \\
{[\mathrm{A}]}\end{array}$ & $\begin{array}{c}\text { Harmonic } \\
\text { Ratios } \\
{[\%]}\end{array}$ \\
\hline 1 & 7.688 & 100 & 15 & 0.246 & 3,21 \\
\hline 3 & 6.048 & 78,68 & 17 & 0.101 & 1,32 \\
\hline 5 & 4.018 & 52,27 & 19 & 0.253 & 3,30 \\
\hline 7 & 2.006 & 26,10 & 21 & 0.181 & 2,36 \\
\hline 9 & 0.709 & 9,23 & 23 & 0,038 & 0,35 \\
\hline 11 & 0.635 & 8,27 & 25 & 0.127 & 1,16 \\
\hline 13 & 0.581 & 7,57 & \multicolumn{3}{|c|}{ THD\% } \\
\hline
\end{tabular}

Table 2 includes harmonic current values and harmonic ratios. Only the 3rd harmonic component's amplitude is equal to $78,68 \%$ of the fundamental component's amplitude value. The THD percentage of the UHFIHS after all calculations is found as $99,22 \%$.

\section{CONCLUSIONS}

This study performs a power quality analysis with the proposed PLL-based digital ANF for a $900 \mathrm{KHz}$ UHFIHS with $2.8 \mathrm{~kW}$ power. A notch filter bank is created using sufficient number of notch filters in the PLL-based measurement system. Due to the superiority of the softwarebased PLL, the synchronization with the fundamental frequency is performed properly. The filter bank is adaptive to deviation in fundamental frequency of the signal and the filter's bandwidth is adjustable. Keeping the bandwidth in a short range prevents leakage of interharmonics, particularly those close to harmonic frequency components. With this proposed method, all components until the 25th harmonic $(\omega 0$, $\omega 3, \ldots \ldots, \omega 25)$, which exist in the current signal, are separately suppressed by the ANF. The signals obtained in each ANF output are subtracted from the input signal, $x(t)$, to calculate the frequency component, $(\omega n)$, of each harmonic. In this way, the leakage effect caused by the interharmonics is prevented and the signal is subjected to a DFT analysis. As a result, frequency and amplitude values of all harmonic components are calculated in a proper, precise and accurate way, in accordance with the IEC standards. The proposed method is found highly successful as it doesn't cause problems like spectral leakage and picket-fence effect, which may lead to calculation errors in FFT and DFT. As a result of the calculations, the total harmonic distortion in the UHFIHS is obtained as $99,22 \%$. This percentage shows a significantly high level of harmonic distortion in the given UHFIHS. Such systems must necessarily be supported with appropriate filter designs that can suppress the target harmonic components. Otherwise, the systems that produce such high-value harmonics can negatively affect other devices connected to the same power supply and result in breakdowns and even permanent damages in these devices.

\section{REFERENCES}

[1] E. Fuchs and M. A. Masoum. Power quality in power systems and electrical machines. Academic press, 2011.

[2] X. Wang, F. Blaabjerg, Harmonic stability in power electronic based power systems: concept, modeling, and analysis. IEEE Transactions on Smart Grid, 2018.

[3] U. Çavdar, "Mechanical properties of hot forged ANSI 1050 steel," Materials Testing, vol.56, no.3, pp. 208-212, 2014. 
[4] H. Gokozan, M. Tastan, S. Taskin, P.S. Cavdar and U. Cavdar, "Comparison of electrical energy consumption for different material processing procedures," Materials Testing, vol. 58, no. 11-12, pp. 10091013, 2016.

[5] M. Taştan, H. Gökozan, S. Taşkin and U. Çavdar, "Comparative energy consumption analyses of an ultra high frequency induction heating system for material processing applications," Revista de metalurgia, vol. 51, no. 3, pp. 46, 2015.

[6] S. Taskin and H. Gokozan, "Determination of the spectral properties and harmonic levels for driving an induction motor by an inverter driver under the different load conditions," Elektronika ir Elektrotechnika, vol. 108, no. 2, pp. 75-80, 2011.

[7] P. K. Ray, P. S. Puhan and G. Panda, "Real time harmonics estimation of distorted power system signal," International Journal of Electrical Power \& Energy Systems, vol. 75, pp. 91-98, 2016.

[8] A. Dalcalı and M. Akbaba, "Detection of the space harmonics of the shaded pole induction motor," Journal of Engineering Research, vol. 5, no. 4, 2018.

[9] T. Jin, Y. Chen and R. C. Flesch, "A novel power harmonic analysis method based on Nuttall-Kaiser combination window double spectrum interpolated FFT algorithm," Journal of Electrical Engineering, vol. 68, no. 6, pp. 435-443, 2017.

[10] D. Belega, D. Petri and D. Dallet, "Impact of harmonics on the interpolated DFT frequency estimator. Mechanical Systems and Signal Processing, vol. 66, pp. 349-360, 2016.

[11] Y. Xia, Y. He, K. Wang, W. Pei, Z. Blazic and D. P. Mandic, "A complex least squares enhanced smart DFT technique for power system frequency estimation," IEEE Transactions on Power Delivery, vol. 32, no. 3, pp. 1270-1278, 2017.

[12] H. Wen, J. Zhang, W. Yao and L. Tang, "Fft-based amplitude estimation of power distribution systems signal distorted by harmonics and noise," IEEE Transactions on Industrial Informatics, vol 14, no. 4, pp. 1447-1455, 2018.

[13] J. Khodaparast and M. Khederzadeh, "Dynamic synchrophasor estimation by taylor-prony method in harmonic and non-harmonic conditions," IET Generation, Transmission \& Distribution, vol. 11, no. 18, pp. 4406-4413, 2017.

[14] S. K. Jain and S. N. Singh, "Exact model order ESPRIT technique for harmonics and interharmonics estimation," IEEE Transactions on Instrumentation and Measurement, vol. 61, no. 7, pp. 1915-1923, 2012.

[15] Y. F. Wang and Y.W. Li, "Three-phase cascaded delayed signal cancellation PLL for fast selective harmonic detection," IEEE Transactions on industrial electronics, vol. 60, no. 4, pp. 1452-1463, 2013.

[16] S. K. Singh, N. Sinha, A. K. Goswami and N. Sinha, "Several variants of Kalman Filter algorithm for power system harmonic estimation," International Journal of Electrical Power \& Energy Systems, vol. 78, pp. 793-800, 2016.
[17] A. Bagheri, M. Mardaneh, A. Rajaei and , A. Rahideh, "Detection of grid voltage fundamental and harmonic components using Kalman filter and generalized averaging method," IEEE Transactions on Power Electronics, vol. 31, no. 2, pp. 1064-1073, 2016.

[18] H. Gokozan, S. Taskin, S. Şeker and H. Ekiz, "A neural network based approach to estimate of power system harmonics for an induction furnace under the different load conditions," Electrical Engineering, vol. 97, no. 2, pp. 111-117, 2015.

[19] F. Vatansever and A. Ozdemir, "An alternative approach for calculating/measuring fundamental powers based on wavelet packet transform and its frequency sensitivity analysis," Electrical Engineering, vol. 91, no. 8, pp. 417-424, 2010.

[20] I. Askarian, S. Eren, M. Pahlevani and A. M. Knight, "Digital RealTime Harmonic Estimator for Power Converters in Future MicroGrids," IEEE Transactions on Smart Grid, vol. 9, no. 6, pp. 6398-6407, 2018.

[21] Y. E. Vatankulu, Z. Şentürk and O. Salor, "Harmonics and Interharmonics Analysis of Electrical Arc Furnaces Based on Spectral Model Optimization With High-Resolution Windowing," IEEE Transactions on Industry Applications, vol. 53, no. 3, pp. 2587-2595, 2017.

[22] A. Özdemir, I. Yazici and C. Vural, "Fast and robust software-based digital phase-locked loop for power electronics applications," IET Generation, Transmission \& Distribution, vol. 7, no. 12, pp. 1435-1441, 2013.

[23] S. Luo and F. Wu, "Improved Two-Phase Stationary Frame EPLL to Eliminate the Effect of Input Harmonics, Unbalance, and DC Offsets," IEEE Transactions on Industrial Informatics, vol. 13, no. 6, pp. 28552863, 2017.

[24] S. Golestan, M. Monfared, F. D. Freijedo and J. M. Guerrero, "Design and tuning of a modified power-based PLL for single-phase gridconnected power conditioning systems," IEEE Transactions on Power Electronics, vol. 27, no. 8, pp. 3639-3650, 2012.

[25] A. Özdemir, M. Taştan, "PLL based digital adaptive filter for detecting interharmonics," Mathematical Problems in Engineering, 2014.

\section{BIOGRAPHIES}

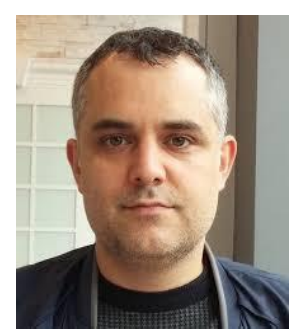

Mehmet TAŞTAN, was born in Afyon, Turkey, in 1977. He received the M.S. degrees in electric and electrical engineering from the University of Niğde Ömer Halisdemir, in 2002 and the Ph.D. degree in electric and electrical engineering from Sakarya University, in 2014. His studies include in power systems, power quality, microcontrollers and signal processing. 